\title{
ACTUALIZACIÓN SOBRE LA INTOXICACIÓN POR WEDELIA GLAUCA (ORT.) HOFFM. EX. HICKEN, ASTERACEAE
}

\author{
Micheloud, J. F. ${ }^{1}$ \& OdRIOZOLA, E. ${ }^{2}$
}

\begin{abstract}
RESUMEN
Wedelia glauca (Ort. Hoffm. ex. Hicken, Asteraceae) es una maleza muy extendida por toda Argentina. Constituye la planta de toxicidad aguda, de mayor importancia en la Pampa húmeda. Si bien es una planta perenne, durante el invierno desaparece la parte aérea, persistiendo los rizomas de un año al otro. Puede propagarse vegetativamente y a través de semillas. Una vez instalada en la pasturas es muy invasora debido a que posee potencial alelopático. Su toxicidad se conserva cuando la planta está seca y el consumo de heno contaminado ha sido asociado con grandes mortandades de animales. Produce una insuficiencia hepática aguda debido a la presencia de un carboxiatractilósido que actúa inhibiendo la fosforilación oxidativa a nivel mitocondrial en los hepatocitos. Se caracteriza clínicamente por salivación, depresión o agresividad que evoluciona rápidamente a la muerte, muchas veces sin signos previos. El hallazgo anatomopatológico más importante es la necrosis periacinar hemorrágica. La presente revisión destaca las características de su ciclo de crecimiento, los mecanismos de lesión celular, las características epidemiológicas de los brotes en la región, y los criterios a tener en cuenta para su diagnóstico.
\end{abstract}

Palabras claves: Wedelia glauca, intoxicación, toxicidad, epidemiología.

\section{SUMMARY}

\section{Update of Wedelia glauca (ORT.) Hoffm. Ex. Hicken, Asteraceae poisoning.}

Wedelia glauca (Ort. Hoffm. ex. Hicken, Asteraceae), is a widespread weed in Argentina. This plant of acute toxicity is the most important in the wet Pampa region. Although it is a perennial plant, the aerial parts disappear during the winter but the rhizomes persist from one year to another. It can be spread vegetatively and by seed. Once in pasture, it is very invasive because of its allelopathic potential. Furthermore, its toxicity is preserved even when the plant is dry and large die-offs have been associated with the consumption of contaminated hay. An acute liver failure is produced due to

1.- Facultad de Ciencias Veterinarias, Universidad Nacional del Litoral. Kreder 2805. (3080) Esperanza, provincia de Santa Fe. E-mail: jmicheloud@yahoo.com.ar

2.- Servicio Especializado de Diagnóstico, INTA EEA Balcarce. Ruta Nacional 226 Km 73,5.

(7620) Balcarce, Buenos Aires, Argentina. E-mail: eodriozola@balcarce.inta.gov.ar

Manuscrito recibido el 8 de marzo de 2012 y aceptado para su publicación el 20 de mayo de 2012. 
the presence of its toxic principle, a carboxyatractyloside that inhibits the oxidative phosphorylation in hepatocyte mitochondrias. It is clinically characterized by salivation, depression or aggression that develops rapidly in death, often with no previous signs. The most important pathological finding is the periacinar hemorrhagic necrosis. This article describes the characteristics of plant growth cycle, how it spreads, the mechanisms of cell injury, the epidemiological characteristics of outbreaks in the region, and the criteria to be considered for diagnosis.

Key Words: Wedelia glauca, poisoning, toxicity, epidemiology.

\section{INTRODUCCIÓN}

Wedelia glauca (W. glauca, Ort. Hoffm. ex.Hicken, Asteraceae), es una maleza perenne ampliamente difundida en la región centro y norte de Argentina, sur de Brasil y Uruguay (Gallo, 1987; Ragonese \& Milano, 1984; Marzocca, 1979). En Argentina produce grandes pérdidas debido a su toxicidad (Oberti et al., 1980) y se enfatiza que es una de las especies tóxicas de mayor importancia (Odriozola, 2003). Además es considerada una de las peores malezas latifoliadas que afecta a los cultivos de maíz, algodón, papa, girasol, alfalfa, montes frutales, huertas, jardines, parques y otros terrenos modificados como orillas de caminos, acequias, baldíos y potreros (Petetin \& Molinari, 1982; Marzocca, 1979). En el año 1932, fue declarada plaga de la agricultura por el decreto de fecha 22-VIII-1932 (Marzocca, 1979). Se la conoce por diversas denominaciones: Yuyo sapo, Suncho, Sunchillo, Espanta Colono, Yuyo Sanjuanino, Clavel Amarillo, Clavel Asolador, Asolador, Sapo, Seca Tierra, Clavelillo, Chilquilla, Catay, Saliet, Seca tierra, etc. (Molina \& Freire, 2009; Marzocca, 1979). El primer reporte de la toxicidad de esta especie fue hecho por Hieronimus en 1882 y luego varios autores efectuaron ensayos de toxicidad en distintas especies, entre estos Spegazzini en 1914; Houssay y Negrete, y Giusti en 1930 (Ragonese \& Milano, 1984). El género Wedelia es de distribución mundial y taxonómicamente forma parte de la Familia Compuestas, Subfamilia Asteroidea. Las asteráceas constituyen uno de los grupos taxonómicos más grandes del reino vegetal y muchas de sus especies son tóxicas (Bruneton, 2001). En Argentina se reconocen 6 especies del género Wedelia (Molina \& Freire, 2009). Aunque sólo se registra como tóxica a $W$. glauca se ha comprobado que extractos de $W$. padulosa tienen efecto citotóxico (Batista et al. 2009). En Australia Wedelia aspérrima es considerada tóxica y es responsable de cuantiosas pérdidas, especialmente en ovinos (Cullen, 2007; Calanasan \& Macleod, 1998; Macleod et al., 1990).

\section{Descripción botánica}

Es una planta perenne, herbácea, rizomatosa, mide de 30 a $80 \mathrm{~cm}$ de altura, con rizomas horizontales largos. Los tallos son largos, erectos y simples o poco ramificados (Molina \& Freire, 2009; Ragonese \& Milano, 1984; Marzocca, 1979). Las hojas son de disposición opuesta, simples, lanceoladas, trinervadas, enteras o pausidentadas, pubescentes y tienen de 7 a $15 \mathrm{~cm}$ de largo (Marzocca, 1979). Estas características constituyen una clave práctica para su identi- 